Reflective Ability, Empathy, and Emotional Intelligence in Undergraduate Social Work Students: A crosssectional study from India

Selwyn Stanley, PhD

Senior Lecturer in Social Work

Faculty of Education, Health \& Wellbeing

University of Wolverhampton, UK, WV1 1AD

selwyn.stanley@wlv.ac.uk

\{Corresponding author\}

$\&$

G. Mettilda Bhuvaneswari, PhD

Asst. Professor of Social Work,

Cauvery College for Women,

Tiruchirappalli, India

narmetm@yahoo.com

Acknowledgement: We thank Dr. V. Sujatha (Principal) and Dr. G. Kanaga (Head, Department of Social Work) of Cauvery College for Women, Tiruchirappalli, India for permission granted and all assistance in collecting data for this study. 


\title{
Reflective Ability, Empathy, and Emotional Intelligence in Undergraduate Social Work Students: A cross-sectional study from India
}

\begin{abstract}
The extant literature indicates that social work is a high stress profession owing to multifarious and complex demands of practice. There is also evidence of stress experienced by student trainees who aspire for a career in social work. Working with service users and the distressing life scenarios encountered on placement often involves negotiating complex emotions and requires reflective skills. Effective practice requires rapport building skills and the ability to demonstrate empathy is a core skill for effective practice. While there is a plethora of Western literature on these issues, the Indian literature has not adequately explored them. Framed against this background, this quantitative study collected data from students of all three years of their undergraduate social work course from a ‘women only’ college in India. Standardised instruments to assess empathy, reflective ability and emotional intelligence were administered. Statistical tests revealed a higher manifestation of these dimensions in final year students than those in the first year. Further it was seen that the total emotional intelligence and empathy scores were positively correlated. Implications of these findings for the education and training of social work students has also been discussed in this article.
\end{abstract}

Key words: Empathy, reflective ability, emotional intelligence, social work students, social work education 


\section{Reflective Ability, Empathy, and Emotional Intelligence in Undergraduate Social Work Students: A cross-sectional study from India}

Social work is a high-stress profession that involves working with people in distressing circumstances such as victims of abuse, domestic violence, substance misuse, crime and other complex life situations (Stanley \& Mettilda, 2015). The rigorous nature of training and high expectations associated with professional conduct, reflective and value-based practice makes social work education a demanding option for student social workers.

Reflection has been considered to be a systematic, rigorous and disciplined way of thinking that has its roots in scientific enquiry and is a process of meaning-making that moves a learner from one experience into the next (Rodgers, 2002). In the context of experiential learning, Dewey (1933) was perhaps one of the earliest to emphasise the importance of reflection in education. A reflective approach to teaching and learning according to him essentially requires the development of reflective thinking which involves curiosity on the part of the learner and a commitment to systematic inquiry (Halton, Murphy, \& Dempsey, 2007). Schon (1983, 1987), on the other hand, considered reflection as a way to improve professional practice by focussing on the content and processes involved therein. He differentiates between 'reflection in practice' as something practitioners do in terms of applying their learning and experience to the current situation that they are dealing with, and 'reflection on practice' as analysis of current situations to draw insights and learning for future practice. Critical reflection has been acknowledged to sharpen social work competence by raising issues relating to how theories, principles and values influence practice and fosters empowerment in service users (Askeland \& Fook, 2009). In our opinion, the western literature on reflection within social work education and practice has grown enormously over the years unlike that in India. Also our experience is that, reflective skills are not consciously embedded within social work pedagogy in India, and elements of reflection are more often than not, inadvertently ingrained in the teaching-learning process.

Empathy has been acknowledged to be a core ingredient in the social worker's repertoire as in other 'helping' professions such as nursing and medicine. It is important for building professional relationships with service users and for understanding and responding to their thoughts and feelings. One of the earliest definitions of this concept, by Dymond (1949, p. 127), is that it involves the "imaginative transposing of oneself into the thinking, feeling, and acting of another person, so structuring the world as he/she does". More recently, writing in a similar vein Trevithick (2005, p. 81) states that "Empathy involves trying to understand, as carefully and sensitively as possible the nature of another person's experience, their own unique point of view and what meaning this conveys for that individual". The importance of accurate empathy in counselling relationships was emphasised by Rogers (2007) who stressed the importance of the therapist experiencing an empathic understanding of the client's internal frame of reference and to communicate this experience to the client. In the context of social work practice, accurate empathy has been considered to have three features namely affective sharing, self-other awareness and the regulation of self-emotion (Gerdes, Lietz, \& Segal, 2011). It is thus essentially an 'other-centered' emotion (Batson, 1991) that involves the cognitive appraisal of another 
individual's inner world. This is in line with the social work philosophy of being 'personcentered' in practice. Underscoring its importance, various professional bodies such as the International Federation of Social workers and the British Association of Social Workers acknowledge empathy to be a core element of practice. While being a skill and an attribute of good practice, the literature also acknowledges its therapeutic benefits for the well-being of service users (Gerdes, Lietz, \& Segal, 2011), the promotion of which is a key function of the social work profession. It gives the service user a sense of reassurance that one is not alone in dealing with problems and difficult life situations and that the social worker is in tune with one's anguish and despair. It conveys the message that one is being appropriately understood and being non-judgementally accepted. While empathy has been universally acknowledged to be a core competence for effective social work practice (Shulman, 2009), actual research on empathy in social work remains 'scarce and sketchy' (Gerdes \& Segal, 2011; Morrison, 2007).

Emotional intelligence (EI) is a concept that encompasses skills of empathy, self-awareness, motivation, self-control and adeptness in relationships (Bar-On, 1997). Salovey and Mayer (1990) were the first to explain the nature of EI and considered it to be a form of social intelligence that involves a person's ability to monitor their own and others' emotions, to discriminate among them and to use that information to guide their thought and actions. It has been defined as 'being able to motivate oneself and persist in the face of frustrations; to control impulse and delay gratification; to regulate one's moods and keep distress from swamping the ability to think; to empathize and to hope' (Goleman, 1995). While Salovey and Mayer (1990) considered EI to be a cognitive ability, others (e.g. Goleman, 1995; Bar-On, 1997) explain it to be a combination of abilities and personality attributes. Goleman, Boyatzis and McKee (2002) consider EI as involving four components namely, self-awareness, self-management, social awareness, and relationship management. EI is significantly associated with the health status of people as shown by a meta-analysis of the extant literature (Schutte, Malouff, Thorsteinsson, Bhullar, \& Rooke, 2007). It is also seen to be related to academic achievement (Parker, Summerfeldt, Hogan, \& Majeski, 2004) and to stress management, problem-solving skills, wellbeing and mental health (Ciarrochi, Deane, \& Anderson, 2002; Gerits, Derksen, Verbruggen, \& Katz, 2005). This background makes EI a valuable variable of study for students of social work, many of whom experience a high level of stress because of the complex demands of their professional education. Understanding and handling one's own and others' emotion is a critical aspect at every stage of the social work task: engagement, assessment, observation, decision making, planning and intervention (Morrison, 2007). While EI has been widely studied in students of nursing and medicine, there is scarce mention of it within the literature on social work students, particularly in India, though it has been termed to be the cornerstone for effective social work practice (Morrison, 2007).

Empathy is a key component of emotional intelligence, and to facilitate its development one needs to provide spaces for emotional thinking (Howe, 2008). Creating a "safe space" that encourages students to share their personal experiences privately and without judgment has also been advocated by Ruben (2015). While the literature on promoting the importance of empathy is plentiful, and empathy is considered to be a crucial skill for social work practice, 
comprehensive discussions about how to specifically cultivate, teach, and learn empathy is not common in the social work literature (Gair, 2011). The same in our opinion can be said of the role of reflective ability in social work education and training. A model to develop empathy in social work students and enhance cross-cultural sensitivity has been described by Pinderhughes, (1979) which involved small group discussion around a set of pre-determined questions. Selfawareness is important for both expressing empathy and for reflective thinking. Bell, Limberg, Jacobson, \& Super (2014) have used experiential play based activities to develop greater selfawareness. Gair (2011), on the other hand, developed an empathy project for social work students using case vignettes for classroom discussion, though in conclusion she admits being disappointed with the effectiveness of the outcome. Milne and Adams (2015) discuss student placements in a care home for older people and conclude that experiential learning in third sector agencies can be structured in a meaningful way to enhance skills of critical reflection in terms of participants' capacity to critically reflect upon their own and others experiences and the nature of care home life and care practice. The use of role plays and classroom simulations could be useful in developing interviewing and empathic skills in social work students (Petracchi, 2015). Power relations understood in terms of Focault's concept of governmentality and how this influences social work practice in terms of being governed, governing oneself, and others, has been used in Australia to develop critical thinking in social work students (Bay \& Macfarlane, 2011). The use of reflective journals has been considered to be a tool to aid the development of the reflective process and as 'a crucible for processing the raw material of experience in order to integrate it with existing knowledge and create new meaning' (Kerka, 2002, p. 1). With the increasing use of technology in higher education, online journaling and active feedback are also important means to nurture reflection (Gursansky, Quinn, \& Le Sueur, 2010).

This study was framed to understand the extent to which reflective ability, empathy and emotional intelligence are manifest in undergraduate social work students in India in different years of their social work degree.

\section{Objectives of the Study}

(1) To portray the socio-demographic profile of undergraduate students of social work in a women's college in Tiruchirappalli, India.

(2) To assess the manifestation of reflective ability, empathy and emotional intelligence in these students.

(3) To compare students of different stages/years of their degree course across these three key study variables.

(4) To ascertain correlations if any between the three key study variables and with sociodemographic variables. 


\section{Methods}

\section{Research Design}

The study is cross-sectional and used survey methodology for data collection. A correlational design has been incorporated to explore significant correlations among variables included in the study. The study is also comparative in nature and compares the manifestation of key variables between students of different year groups.

\section{Measures}

(1) Self-prepared schedule to collect socio-demographic data.

(2) Groningen Reflective Ability Scale (GRAS) developed by Aukes, Geertsma, CohenSchotanus, Zwierstra, and Slaets (2007) has 23 items that measures three sub-dimensions namely self-reflection, empathetic reflection and reflective communication. The items are measured on 5-point Likert scales with responses ranging from totally disagree to totally agree. Higher scores indicate higher reflective ability. As reported by the authors, the GRAS has a satisfactory internal consistency: A Cronbach's alpha of .83 for the 1st measurement (step 4) and .74 for the 2nd measurement (step 4), an item-difficulty (between 4.23 and 3.50) and item variance (between 1.04 and 0.67). For the current sample, the Cronbach's alpha was calculated to be .778, which is an 'acceptable' level of internal consistency reliability for the scale (George \& Mallery, 2003).

(3) Empathy Assessment Index (EAI) by Lietz, Gerdes, Sun, Geiger, Wagaman, and Segal, (2011) is a 17 Item validated self-report measure that has five sub-dimensions namely, Affective Response, Emotion Regulation, Perspective Taking, Self-Other Awareness and Empathic Attitudes. Items are scored on a six point Likert scale (from never $=1$ to always=6) with higher scores indicating higher levels of empathy. The 17-item EAI version has excellent internal consistency $(\alpha=.823)$ and strong test-retest reliability as ascertained by the authors. In this study the Cronbach's alpha was .804, which is considered to be 'good' in terms of reliability (George \& Mallery, 2003).

(4) Emotional Intelligence Scale (EIS) by Schutte, Malouff, Hall, Haggerty, Cooper, Golden, and Dornheim (1998) is a 33 item instrument that measures three sub-dimensions namely: appraisal and expression of emotion, regulation of emotion and utilization of emotion. The items are measured on 5-point Likert scales with responses ranging from strongly disagree (score 1) to strongly agree (score 5). Higher scores indicate higher emotional intelligence. Internal consistency analysis by the authors of the instrument showed a Cronbach's alpha of .90 for the 33-item scale and sound test-retest reliability, predictive validity, and discriminant validity as well. In the current study the alpha computed was .871 which is considered 'good' in terms of reliability (George \& Mallery, 2003). 


\section{Setting of the Study}

Cauvery College is an exclusive college for women in Tiruchirappalli city (Trichy in short), in the state of Tamilnadu in South India. It is a self-financing college (receives no Government aid), that was established in 1984 and is run by a private educational trust and caters to about 4000 students at all levels. It is an arts and science college affiliated to the Bharathidasan University which offers the degree for the fourteen undergraduate and nine postgraduate courses including social work offered by the college.

\section{Insert Table 1 about here}

\section{Data collection and ethical issues}

Table 1 depicts students enrolled and enlisted as respondents distributed by their year of study on the social work degree. A total of 73 social work students across the three years of the undergraduate degree provided the data for the study. No sampling procedure was used. Students of each cohort were briefed about the study in advance and pre-determined dates for data collection were announced during the briefing. The difference in student numbers for those enrolled on the degree and those enlisted as respondents (table 1), is owing to absence on the day of data collection. Permission was obtained from the Principal of the college and the ethics review panel of the institution cleared the protocol of the study. Students were told that participation in the study was voluntary and that non-participation would in no way influence their academic life. Informed consent forms were obtained from all who expressed willingness to provide data and absolute confidentiality was assured. The second author collected the data from each cohort on the previously announced dates at the start of the academic year in June 2015. She provided clarifications relating to the items of the questionnaires as required. The importance of completing all scale items was emphasised to avoid having to contend with missing data and having to make necessary adjustments during analysis. Questionnaires on receipt were cross-checked to ensure that we did not have to deal with this issue. Students were not required to provide their name or any other personal identifying data in order to maintain anonymity and to encourage honest responses.

\section{Results}

\section{Profile of respondents}

In keeping with the demographics of Trichy city, the vast majority of the respondents hailed from Hindu families (90.4\%) and the remaining from a Christian background. Though Trichy has a sizeable Muslim population, none of the respondents belonged to this community. The mean age of the respondents was 18.59 and ranged from 16 to 24 years, the majority (68.5\%) were in the 18-19-year age group. The majority (68.5\%) of students came from a rural background and from nuclear families (83.6\%), which means these respondents were living with siblings and/or parents. $43.8 \%$ of them had only one sibling and $46.6 \%$ were the eldest child in the family. The vast majority (79.5\%) had previously gone to schools where the medium of instruction was Tamil (vernacular) and the remaining had attended English medium schools. The majority of these schools (57.5\%) were located in rural areas. The majority of respondents 
(78.1\%) while they were in school, lived with their parents, but currently after moving to college, only 64.4 per cent do so and the remaining stayed/were staying in student hostels. Educational background of parents was considerably low with the majority of parents having studied at different levels up to higher secondary school. $2.7 \%$ of fathers and $15 \%$ of mothers had never been to school. The father was the main breadwinner in most families and the majority $(50.7 \%)$ were engaged in farming or employed as casual labourers (called 'coolie' in Tamil), while the majority $(76.7 \%)$ of mothers were not in paid employment. The reported total monthly family income ranged from Rupees 1000 to 70,000 with a mean of Rupees 11,100 (approx. 164 USD) per month. The overall profile of the respondents shows a predominantly rural lower middleclass background and having low levels of parental education and income.

Regarding their motivation to do a social work degree, the majority reported it was encouragement received from family and friends (56\%) that had spurred them to join the social work degree and thirty percent said they were influenced by their former teachers. When the $2^{\text {nd }}$ and $3^{\text {rd }}$ year students were asked if the course had changed them in any way, some of the responses received were that it had increased their awareness of social problems (23\%); they had developed a more helping attitude (24\%), and that their behaviour (13\%), and attitude (8\%) towards others had considerably changed. 24 percent however felt that the course had not brought about any significant change in them. The majority (84\%) said their ambition was to become a social worker or counsellor in a 'good' organisation and felt that they had made the right choice in joining the social work course (98.6\%). They used words like happy (16.4\%), interesting (27.4\%), and useful $(24.7 \%)$ when asked about their social work degree program.

\section{Insert Table 2 about here}

\section{Reflective Ability, Empathy and Emotional Intelligence}

The mean scores obtained by students on the three scales administered as well as their component sub-dimensions are depicted in Table 2. It is seen that for the total scores of all three scales, students in the first year have lower scores than those in the third (final) year. The component sub-dimensions for each scale also show a similar trend except for the 'affective response' component of the EAI where there is a slight decrease in third year mean scores when compared to year 1 .

\section{Insert Table 3 about here}

ANOVA tests were carried out for all the subject dimensions to assess any statistically significant differences between the three year groups and these results are portrayed in Table 3 . As the number of tests carried out was large (fourteen) we applied the Bonferoni correction to check the significance ( $\mathrm{p}$ value), in order to avoid Type I errors and the revised significance threshold was set at $p<.003$. Significant statistical differences are seen in terms of the total scores for reflective ability and emotional intelligence across the three years. No significant differences were seen between the three cohorts on the component scores of all three key variables.

\section{Insert Table 4 about here}




\section{Comparisons based on select background variables}

Respondents were compared among themselves based on their place of residence (rural/urban); previous medium of instruction (English/Tamil); current residential status (Hostel/day scholar) and religion (Hindu/Christian) to see if they differed in the manifestation of the subject dimensions based on these background factors. Student $t$ tests were used for these comparisons and the results for the total scores for each dimension are depicted in Table 4. It is seen that there is no statistically significant difference in terms of the religious affiliation of the respondents and the total score of all three subject dimensions. There is however a significant difference for respondents classified according to their place of residence (rural/urban) in terms of their reflective ability but not for the total empathy or emotional intelligence scores. This is also true when they were divided and compared across their previous medium of instruction in school (English/Tamil) and current residential status (Hostel/Day scholar). Mean score comparisons for reflective ability indicate a higher mean for students from urban areas, those whose previous medium of instruction was Tamil and those who resided in student hostels.

\section{Inter-correlations among variables}

Insert Table 5 about here

Pearsons product moment correlations were computed among the subject dimensions and their components and the results are shown in Table 5. We have applied the Bonferoni correction to set the threshold for checking significant correlations, in the light of the number of variables being analysed, in order to minimise Type I errors and the level of significance was reset at $p<$ .003 . While it is not surprising to see several inter-correlations between component subdimensions of the same scale or with its total score, what is of interest is to examine correlations between total scale scores or between the respective components of various measures and we have highlighted some of these here. In terms of total scores for the three key variables, a significant positive correlation is seen between the Total Emotional Intelligence (EIS) and Total Empathy (EAI) scores. The Total Reflective Ability score did not enter into any significant correlation with either the EIS or the EAI scores. The EIS scores show a significant positive correlation with the 'perspective taking' and 'self-other awareness' domains of the EAI. The total EAI scores also correlate positively with the 'appraisal and regulation of emotions' domain of the EIS. The latter EIS domain correlates positively with the 'self-other awareness' and 'perspective taking' domains of the EAI. The GRAS and its three components do not correlate with any other component domains of the EIS or the EAI.

In terms of correlations between sociodemographic variables and the dimensions studied, the age of the respondents correlated significantly with the total score of only the reflective ability scale $(\mathrm{r}=.37 ; \mathrm{p}=.001)$. No other significant correlations were seen between either age, respondents' birth order, or the number of siblings and the total scores of all three scales or any of their component domains. 


\section{Limitations of the study}

The study being cross-sectional in nature does not provide an understanding if the variables studied change over time as students' progress from admission to graduation in their social work course. Data collection is now in progress for a longitudinal study with social work students in year one to examine if any of the key variables change over time as they move into years two and three of their degree.

Also the lack of a comparative group of students from other undergraduate disciplines does not permit analysis relating to whether the dimensions of study are higher or lower in social work students.

Data was collected only from women students and hence comparisons based on gender were not possible.

The study has not taken into account personality variables that could influence the three key variables of the study.

Generalisations are limited owing to the study having been carried out in only one college in India and is restricted by cultural variations, differences in taught content and placement experiences elsewhere.

In spite of these limitations, we feel that this piece of work is an important contribution to the extant literature on the key variables studied, particularly in the Indian context.

\section{Implications for social work education and training}

It was seen in this study that students in their first year of study obtained significantly lower scores on all the three subject dimensions than those in their final year. The cross-sectional nature of this study does not permit the inference that these variables have increased in their manifestation as students' progress through their course. However it does indicate that $1^{\text {st }}$ year students may require more assistance in sharpening their reflective and empathic ability. The need to develop these skills ought to be emphasised in the very first year of the course and throughout their studies so that it becomes a conscious element of their professional repertoire. Students need to realise the importance and relevance of developing skills of reflection and empathy for their practice and how this will shape them into more competent and effective social workers. If we accept the premise that all 'skills' can be developed through rehearsal and practice, the implication in the context of this study would be that reflective ability and empathy, considered to be cardinal skills of social work can also be sharpened and developed. These skills could be honed during supervision with their tutors and also through small group classroom activities such as enactment of role plays using life scenarios potentially encountered in practice.

As new comers to the degree, students may not be adept in skills of critical enquiry and reflection. The placement reports of students in India tend to be largely descriptive, almost a summary of their activities with hardly any shades of in-built reflection. Reflective habits need to be taught and educators must not simply assign reflection to students (Spalding \& Wilson, 2002). Critical reflection on values, principles, theories and trends in practice is an important aspect of professional growth and needs to be fostered in students. The onus is on the tutors who during supervisory sessions can ask questions such as 'So what have you learnt from this?', 'How does 
it relate to the theories that you have learnt?', Is there another way of intervening in this particular scenario?', 'What else might you have done?' or 'what could you have done differently in this scenario?'. Such questions could stimulate reflective thinking and critical analysis in students. Such an approach could be particularly of benefit to those new to the course to help them slip into a more reflective mode of analysis. Sustained and consistent supervision on these lines could enable students to build in reflection almost automatically by default into their analysis of practice. How moral and value-based thinking is incorporated into effective and responsible professional practice' (Fook, Ryan, \& Hawkins, 2000) is the hallmark of a good professional. Structured, mentored reflection offers the opportunity to examine underlying philosophies or 'meaning', assess their usefulness in the context of social work practice, and to consider alternative approaches based on other philosophies (Halton, Murphy, \& Dempsey, 2007). Critical reflection also involves challenging existing social, political and cultural conditions (Spalding \& Wilson, 2002; Yip, 2006) and students need to be encouraged to consider these influences on their service users and professional practice. Students also have to realise that their encounters in practice often involve complex and ambiguous tasks, which can be better dealt with through engaging in action and reflecting on that action (Hughes \& Heycox, 2005). The importance of self-reflection merits emphasis. Students ought to be encouraged to maintain journals or diaries in which to jot down their thoughts and feelings relating to their engagement with service users and the situations that they encounter on placement. The importance of these tools have been advocated to assist in developing the reflective process and has been considered to be a crucible for processing experience and to integrate it with existing knowledge, in order to create new meaning and insights (Kerka, 2002).

Like reflective ability, skills of empathy can also be taught and enhanced. Empathy can be taught, increased, refined and mediated to make helping professionals more skilful and resilient (Gerdes \& Segal, 2011). The message that social work cannot be effective without a positive relationship with service users and that empathy forms the basis of this relationship, has to be conveyed consistently, and with persistence. Empathy is not possible without effective communication and so techniques to improve verbal communication in students and demonstrating appropriate words and phrases to effectively communicate their thoughts and feelings is a necessary element of good social work training. The teaching of empathy in India is done rather cursorily with the teacher mostly 'lecturing' about its meaning, components and importance, unlike in the West where students have the benefit of communication labs, video recording and play back and of conducting actual or mock conversations with service users through role plays. It is important that skills of empathy are demonstrated and sharpened through the use of role plays and case scenarios, even if the technological adjuncts required are not available in the Indian context. Students also have to be made aware of the ills of overidentification with service users and how emotional enmeshment may lead to compassion fatigue and burn out (Eisenberg, 2000). The importance of maintaining perceptual boundaries has to be stressed as social workers who do not do so risk experiencing the other's feelings of anger, anxiety or depression as their own (Gerdes \& Segal, 2011). This is why self-other awareness and boundary maintenance becomes important in social work training and placement supervision 
becomes a valuable medium to help students see if they are staying within professional boundaries or stepping over the line.

It was also seen in this study, that the dimensions of reflective and empathetic ability predicted the manifestation of EI. This implies that developing reflective skills and empathetic understanding and expression is vital in terms of developing EI in students. Strong relationships have been found between emotional intelligence, reflective ability and empathy, and psychological health and resilience (Grant \& Kinman, 2012). Several studies have indicated that levels of psychological distress are high in social work students (Stanley \& Mettilda, 2015; Harr $\&$ Moore, 2011). Historically, the social work curriculum has placed little emphasis on the emotional nature of the work, or the need for students to develop their emotion management skills (Grant, Kinman, \& Alexander, 2014). This is despite the fact that for many students, placement experiences could be harrowing as they often encounter distressing situations relating to abuse, extreme poverty and other traumatic life events in service users. EI is considered an important aspect for effective stress management (Slaski \& Cartwright, 2003; Gohm, Corser, \& Dalsky, 2004). If students are not adequately prepared for the emotional realities of practice, they could develop 'defensive manoeuvres' which may negatively impact their wellbeing, job performance and retention (Dwyer, 2007). EI has also been considered to underpin five core aspects of social work practice namely engagement, assessment and observation, decision making, collaboration and cooperation and dealing with stress, developing coping strategies, and resilience (Morrison, 2007). The importance of emotional intelligence for social work students can hence not be overemphasised. Focussing on the emotional elements of their experiences on placement is thus an important aspect of student supervision. This could generate deeper insight and understanding of what emotions were experienced in different contexts, how they were regulated and expressed, their appropriateness and influence on one's behaviour and engagement with others. This would in the long run help develop social workers who show reflective ability, have appropriate skills of empathy and are emotionally competent.

\section{Conclusion}

This cross-sectional study involved undergraduate social work students from India who were administered standardised instruments to assess their reflective ability, extent of empathy and emotional intelligence. They were compared across their year of study. It was seen that while these variables were manifest to a lesser extent in first year students, they were higher in their final year of study. The three dimensions were interrelated and it was seen that reflective and empathetic ability predicted the manifestation of emotional intelligence. It is important for social work training to consciously focus on enhancing these aspects in students through supervision and other small group activity to enable them to develop effective practice skills and to flourish as competent professionals. 


\section{References}

Askeland, G. A., \& Fook, J. (2009). Critical reflection in social work. European Journal of Social Work, 12, 287-292.

Aukes, L.C., Jelle Geertsma, J., Janke Cohen-Schotanus, J., Rein P. Zwierstra, R.P., \& Slaets, J.P.J. (2007). The development of a scale to measure personal reflection in medical practice and education. Medical Teacher, 29, 177-182.

Bar-On, R. (1997). The Emotional Intelligence Inventory (EQ-i): technical manual. Toronto, Canada: Multi-Health Systems.

Batson, C. D. (1991). The altruism question: Toward a social-psychological answer. Hillsdale, NJ: Erlbaum Associates.

Bay, U., \& Macfarlane, S. (2011). Teaching Critical Reflection: A Tool for Transformative Learning in Social Work?, Social Work Education, 30, 745-758.

DOI: $10.1080 / 02615479.2010 .516429$

Bell, H., Limberg, D., Jacobson, L., \& Super, J. (2014). Enhancing self-awareness through creative experiential-learning play-based activities. Journal of Creativity in Mental Health, 9, 399-414.

Ciarrochi, J., Deane, F.P., \& Anderson, S. (2002). Emotional intelligence moderates the relationship between stress and mental health. Personality and Individual Differences, 32, 197 209.

Dewey, J. (1933). How We Think: A Restatement of Reflective Thinking to the Educative Process. Boston: D. C. Heath. (Original work published in 1910)

Dwyer, S. (2007). The emotional impact of social work practice. Journal of Social Work Practice, 21, 49-60. doi:10.1080/02650530601173607

Dymond, R. F. (1949). A scale for the measurement of empathic ability. Journal of Consulting Psychology, 13, 127-133. http://dx.doi.org/10.1037/h0061728

Eisenberg, N. (2000). Emotion, regulation, and moral development. Annual Review of Psychology, 51, 665-697.

Fook, J., Ryan, M., \& Hawkins, L. (2000). Professional Expertise: Practice, theory and education for working in uncertainty. London: Whiting \& Birch

Gair, S. (2011). Creating spaces for critical reflection in social work education: Learning from a classroom based empathy project. Reflective Practice, 12, 791-802.

[DOI:10.1080/14623943.2011.601099]

George, D., \& Mallery, P. (2003). SPSS for Windows step by step: A simple guide and reference. 11.0 update (4th ed.). Boston: Allyn \& Bacon. 
Gerdes, K. E., Lietz, C., \& Segal, E. A. (2011). Measuring empathy in the 21st century: The development of an empathy index rooted in social cognitive neuroscience and social justice. Social Work Research, 35, 83-93.

Gerdes, K. E., \& Segal, E. (2011). Importance of empathy for social work practice: Integrating new science. (2011). Social Work, 56, 141-148. Doi:10.1093/sw/56.2.141

Gerits, L., Derksen, J. L., Verbruggen, A. B., \& Katz, M. (2005). Emotional intelligence profiles of nurses caring for people with severe behavior problems. Personality and Individual Differences, 38, 33-43.

Gohm, C.L., Corser, G.C., \& Dalsky, D.J. (2004). Emotional intelligence under stress: Useful, unnecessary, or irrelevant? Personality and Individual Differences, 39, 1017-1028.

Goleman, D. (1995). Emotional Intelligence: why it can matter more than IQ. New York: Bantam Books.

Goleman, D., Boyatzis, R., \& McKee, A. (2002). Primal leadership: Realizing the power of emotional intelligence. Boston: Harvard Business School.

Grant, L., \& Kinman, G. (2012). Enhancing wellbeing in social work students; building resilience in the next generation. Social Work Education: The International Journal, 31, 605621. [DOI.org/10.1080/02615479.2011.590931]

Grant, L., Kinman, G., \& Alexander, K. (2014). What's All this Talk About Emotion? Developing Emotional Intelligence in Social Work Students, Social Work Education, 33, 874-889. DOI: 10.1080/02615479.2014.891012

Gursansky, D., Quinn, D., \& Le Sueur, E. (2010). Authenticity in Reflection: Building Reflective Skills for Social Work. Social Work Education, 29, 778-791.

DOI: $10.1080 / 02615471003650062$

Halton, C., Murphy, M., \& Dempsey, M. (2007). Reflective learning in social work education: researching student experiences. Reflective Practice: International and Multidisciplinary Perspectives, 8, 511- 523.

Harr, C., \& Moore, B. (2011). Compassion fatigue among social work students in field placements. Journal of Teaching in Social Work, 31, 350-363. doi: $10.1080 / 08841233.2011 .580262$

Howe, D. (2008). The Emotionally Intelligent Social Worker. Basingstoke: Palgrave

Hughes, M. \& Heycox, K. (2005). Promoting reflective practice with older people: Learning and teaching strategies. Australian Social Work, 58, 344-356.

doi:10.1111/j.1447-0748.2005.00231.x 
Kerka, S. (2002). Teaching Adults: Is It Different? Center on Education and Training for Employment, College of Education, the Ohio State University. Available at, http://files.eric.ed.gov/fulltext/ED468614.pdf (Accessed: 15/01/2016)

Lietz, C.A., Gerdes, K.E., Sun, F., Geiger, J.M., Wagaman, A.M., \& Segal, E.A. (2011). The empathy assessment index (EAI): A confirmatory factor analysis of a multidimensional model of empathy. Journal of the Society for Social Work Research, 2, 104-124.

Milne, A. \& Adams, A. (2014). Enhancing Critical Reflection amongst Social Work Students: The Contribution of an Experiential Learning Group in Care Homes for Older People. Social Work Education: The International Journal, 34, 74-90.

DOI: $10.1080 / 02615479.2014 .949229$

Morrison, T. (2007). Emotional Intelligence, Emotion and Social Work: Contexts,

Characteristics, Complications and Contribution. British Journal of Social Work, 37, 245-263.

Parker, J.D.A., Summerfeldt, L.J., Hogan, M.J., \& Majeski, S.A. (2004). Emotional differences and academic success: examining the transition from high school to university. Personality and Individual Differences, 36, 163 - 172.

Petracchi, H.E. (2015). Using Professionally Trained Actors in Social Work Role-Play Simulations. The Journal of Sociology \& Social Welfare, 26, 61-69.

Pinderhughes, E.B. (1979). Teaching empathy in cross-cultural social work. Social Work, 24, 312-316.

Ruben, J. (2015). Can Social Work Students Learn Empathy? Social Work Today, 15, 12. Rodgers, C. (2002). Defining Reflection: Another look at John Dewey and reflective thinking. Teachers College Record, 104, 842-866.

Rogers, C. R. (2007). The necessary and sufficient conditions of therapeutic personality change. Psychotherapy: Theory, Research, Practice, Training, 44, 240-248. (Original publication: Journal of Consulting Psychology, 1957, 2, 95-103).

Salovey, P., \& Mayer, J.D. (1990). Emotional Intelligence. Imagination, Cognition and Personality, 9, 185-211.

Schön, D. A. (1983). The Reflective Practitioner. London, Temple Smith

Schön, D. A. (1987). Educating the Reflective Practitioner. San Fransisco, Jossey Bass

Schutte, N.S., Malouff,J.M., Hall, L.E., Haggerty, D.J., Cooper, J.T., Golden, C.J., \& Dornheim, L. (1998). Development and validation of a measure of emotional intelligence. Personality and Individual Differences, 25, 167-177.

Schutte, N.S., Malouff, J.M., Thorsteinsson, E.B., Bhullar, N., \& Rooke, S.E. (2007). A metaanalytic investigation of the relationship between emotional intelligence and health. Personality and Individual Differences, 42, 921-933. 
Shulman, L. (2009). The skills of helping individuals, families, groups, and communities, 6th edition. Belmont, CA: Brooks/Cole.

Slaski, M., \& Cartwright, S. (2003). Emotional intelligence training and its implications for stress, health and performance. Stress and Health, 19, 233-239.

Spalding, E., \& Wilson, A. (2002). Demystifying reflection: A Study of pedagogical strategies that encourage reflective journal writing. Teachers College Record, 104, 1393-1421.

Stanley, S., \& Mettilda, G.B. (2015). Stress, Anxiety, Resilience and Coping in Social Work Students (A Study from India). Social Work Education: The International Journal.

DOI: $10.1080 / 02615479.2015 .1118451$

Trevithick, P. (2005). Social Work Skills: A Practice Handbook. $2^{\text {nd }}$ edn. Maidenhead: Open University Press

Yip, K. (2006). Self-reflection in Reflective Practice: A note of caution. British Journal of Social Work, 36, 777-788. Doi: 10.1093/bjsw/bch323 


\section{Table 1}

Table depicting the number of students enrolled and enlisted for the study

\begin{tabular}{lcc}
\hline Year/Stage of study & $\begin{array}{c}\text { Students enrolled } \\
\text { (on the degree) }\end{array}$ & Respondents \\
\hline 1 & 39 & 34 \\
2 & 32 & 22 \\
3 & 28 & 17 \\
\hline Total & 99 & 73
\end{tabular}


Table 2

Distribution of respondents by mean scores on subject dimensions and year of study

\begin{tabular}{|c|c|c|c|c|c|c|c|c|c|c|c|c|c|c|c|}
\hline $\begin{array}{l}\text { Year of } \\
\text { Study }\end{array}$ & & $\begin{array}{c}\text { Self- } \\
\text { reflection }\end{array}$ & $\begin{array}{l}\text { Empathic } \\
\text { reflection }\end{array}$ & $\begin{array}{c}\text { Reflective } \\
\text { Communication }\end{array}$ & $\begin{array}{c}\text { Total } \\
\text { Reflective } \\
\text { Ability } \\
\end{array}$ & $\begin{array}{l}\text { Affective } \\
\text { Response }\end{array}$ & $\begin{array}{l}\text { Emotional } \\
\text { Regulation }\end{array}$ & $\begin{array}{l}\text { Perspective } \\
\text { Taking }\end{array}$ & $\begin{array}{l}\text { Self-Other } \\
\text { Awareness }\end{array}$ & $\begin{array}{l}\text { Empathetic } \\
\text { Attitudes }\end{array}$ & $\begin{array}{c}\text { Total } \\
\text { Empathy } \\
\text { Score } \\
\end{array}$ & $\begin{array}{l}\text { Appraisal of } \mathrm{I} \\
\text { emotions }\end{array}$ & $\begin{array}{l}\text { Regulation of } \\
\text { emotions }\end{array}$ & $\begin{array}{c}\text { Utilisation } \\
\text { of } \\
\text { emotions }\end{array}$ & $\begin{array}{c}\text { Total } \\
\text { Emotional } \\
\text { Intelligence }\end{array}$ \\
\hline \multirow[b]{2}{*}{1} & Mean & 34.59 & 22.18 & 24.41 & 81.18 & 15.62 & 14.50 & 12.47 & 12.32 & 11.15 & 66.06 & 45.85 & 40.59 & 39.41 & 125.82 \\
\hline & $\begin{array}{l}\text { Std. } \\
\text { Deviation }\end{array}$ & 4.51 & 3.57 & 3.64 & 5.49 & 2.72 & 3.87 & 5.13 & 3.20 & 2.58 & 12.63 & 5.54 & 1.88 & 2.96 & 6.10 \\
\hline \multirow[b]{2}{*}{2} & Mean & 37.06 & 21.41 & 26.18 & 84.65 & 15.18 & 12.94 & 13.71 & 13.35 & 12.18 & 67.35 & 48.77 & 41.82 & 40.94 & 131.53 \\
\hline & $\begin{array}{l}\text { Std. } \\
\text { Deviation }\end{array}$ & 4.93 & 2.90 & 1.78 & 7.31 & 2.72 & 4.51 & 4.24 & 3.16 & 3.15 & 13.00 & 3.19 & 3.70 & 1.82 & 6.37 \\
\hline \multirow{2}{*}{3} & Mean & 38.68 & 24.59 & 26.46 & 89.73 & 15.18 & 17.05 & 16.32 & 14.14 & 13.50 & 76.18 & 49.23 & 42.50 & 41.59 & 133.55 \\
\hline & $\begin{array}{l}\text { Std. } \\
\text { Deviation }\end{array}$ & 5.65 & 4.08 & 2.76 & 7.47 & 3.75 & 4.28 & 3.51 & 2.42 & 3.16 & 12.24 & 6.09 & 3.65 & 1.62 & 6.66 \\
\hline
\end{tabular}


Table 3

One Way Analysis of Variance based on Year of Study for all Subject Dimensions

\begin{tabular}{|c|c|c|c|c|c|}
\hline Dimensions & & $\begin{array}{l}\text { Sum of } \\
\text { Squares }\end{array}$ & Mean Square & $\mathrm{F}$ & $\begin{array}{l}\text { Significance } \\
\text { (Bonferoni } \\
\text { corrected)* }\end{array}$ \\
\hline \multirow{2}{*}{$\begin{array}{l}\text { Self } \\
\text { Reflection }\end{array}$} & Between Groups & 233.53 & 116.76 & 4.72 & .012 \\
\hline & Within Groups & 1729.94 & 24.71 & & \\
\hline \multirow{2}{*}{$\begin{array}{l}\text { Empathic } \\
\text { reflection }\end{array}$} & Between Groups & 116.14 & 58.07 & 4.49 & .015 \\
\hline & Within Groups & 904.37 & 12.92 & & \\
\hline \multirow{2}{*}{$\begin{array}{l}\text { Reflective } \\
\text { Communication }\end{array}$} & Between Groups & 67.81 & 33.90 & 3.66 & .031 \\
\hline & Within Groups & 648.16 & 9.25 & & \\
\hline \multirow{2}{*}{$\begin{array}{l}\text { Total Reflective } \\
\text { Ability }\end{array}$} & Between Groups & 976.78 & 488.39 & 11.30 & $.000 *$ \\
\hline & Within Groups & 3023.18 & 43.18 & & \\
\hline \multirow{2}{*}{$\begin{array}{l}\text { Affective } \\
\text { Response }\end{array}$} & Between Groups & 3.48 & 1.74 & 0.18 & .831 \\
\hline & Within Groups & 657.77 & 9.39 & & \\
\hline \multirow{2}{*}{$\begin{array}{l}\text { Emotional } \\
\text { Regulation }\end{array}$} & Between Groups & 171.93 & 85.96 & 4.99 & .009 \\
\hline & Within Groups & 1204.39 & 17.20 & & \\
\hline \multirow{2}{*}{ Perspective Taking } & Between Groups & 198.73 & 99.36 & 4.91 & .010 \\
\hline & Within Groups & 1414.77 & 20.21 & & \\
\hline \multirow{2}{*}{$\begin{array}{l}\text { Self-other } \\
\text { Awareness }\end{array}$} & Between Groups & 45.20 & 22.60 & 2.55 & .085 \\
\hline & Within Groups & 619.91 & 8.85 & & \\
\hline \multirow{2}{*}{$\begin{array}{l}\text { Empathetic } \\
\text { Attitudes }\end{array}$} & Between Groups & 74.09 & 37.04 & 4.40 & .016 \\
\hline & Within Groups & 588.23 & 8.40 & & \\
\hline \multirow{2}{*}{$\begin{array}{l}\text { Total Empathy } \\
\text { Score }\end{array}$} & Between Groups & 1462.63 & 731.31 & 4.60 & .013 \\
\hline & Within Groups & 1115.03 & 158.78 & & \\
\hline \multirow{2}{*}{$\begin{array}{l}\text { Appraisal } \\
\text { of emotions }\end{array}$} & Between Groups & 184.89 & 92.44 & 3.30 & .042 \\
\hline & Within Groups & 1957.18 & 27.96 & & \\
\hline \multirow{2}{*}{$\begin{array}{l}\text { Regulation } \\
\text { of emotions }\end{array}$} & Between Groups & 51.87 & 25.93 & 2.95 & .059 \\
\hline & Within Groups & 614.20 & 8.77 & & \\
\hline \multirow{2}{*}{$\begin{array}{l}\text { Utilisation of } \\
\text { emotions }\end{array}$} & Between Groups & 69.34 & 34.67 & 6.12 & .004 \\
\hline & Within Groups & 396.49 & 5.66 & & \\
\hline \multirow{2}{*}{$\begin{array}{l}\text { Total Emotional } \\
\text { Intelligence }\end{array}$} & Between Groups & 889.58 & 444.79 & 11.08 & $.000 *$ \\
\hline & Within Groups & 2808.63 & 40.12 & & \\
\hline
\end{tabular}


Table 4

t test results on subject dimensions and selected socio-demographic variables

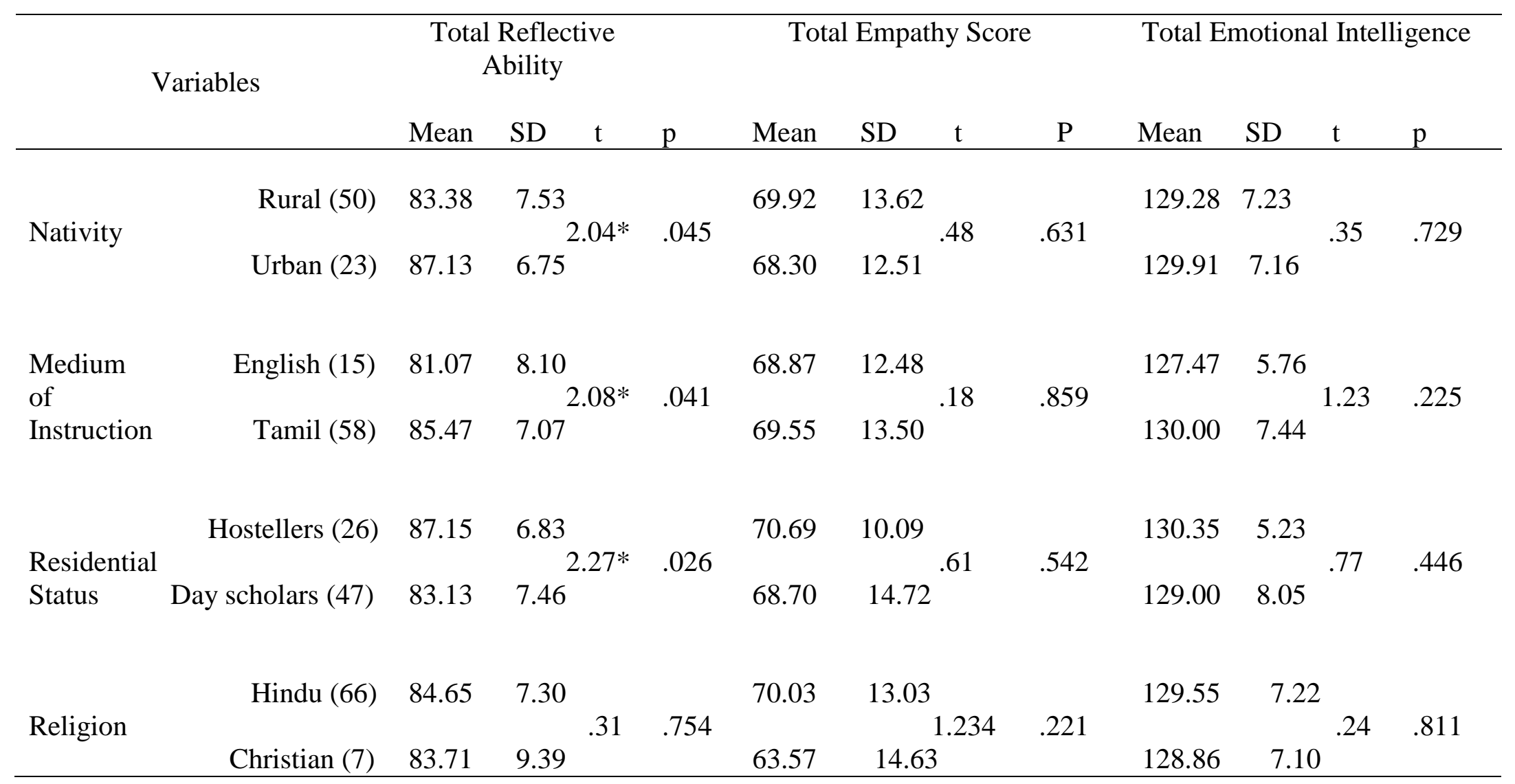

Note: Figures in parentheses are respondent numbers

$\mathrm{N}=73 ; \mathrm{df}=71 ; \mathrm{p}<.05^{*}$ 


\section{Table 5}

Inter-correlation matrix for subject dimensions and their components (with Bonferoni correction)*

\begin{tabular}{|c|c|c|c|c|c|c|c|c|c|c|c|c|c|c|}
\hline $\begin{array}{l}\text { Subject } \\
\text { Dimensions }\end{array}$ & 1 & 2 & 3 & 4 & 5 & 6 & 7 & 8 & 9 & 10 & 11 & 12 & 13 & 14 \\
\hline 1. Self-reflection & 1 & & & & & & & & & & & & & \\
\hline $\begin{array}{l}\text { 2. Empathetic } \\
\text { reflection }\end{array}$ & -.11 & 1 & & & & & & & & & & & & \\
\hline $\begin{array}{l}\text { 3. Reflective } \\
\text { communication }\end{array}$ & .04 & .30 & 1 & & & & & & & & & & & \\
\hline $\begin{array}{l}\text { 4. Total Reflective } \\
\text { Ability Score }\end{array}$ & $.66^{*}$ & $.55^{*}$ & $.61 *$ & 1 & & & & & & & & & & \\
\hline $\begin{array}{l}\text { 5. Appraisal \& } \\
\text { expression of } \\
\text { emotion }\end{array}$ & .16 & .05 & .02 & .15 & 1 & & & & & & & & & \\
\hline $\begin{array}{l}\text { 6. Regulation of } \\
\text { emotion }\end{array}$ & .14 & .15 & .06 & .19 & .12 & 1 & & & & & & & & \\
\hline $\begin{array}{l}\text { 7. Utilisation of } \\
\text { emotion }\end{array}$ & .04 & -.01 & .21 & .11 & .01 & 0.18 & 1 & & & & & & & \\
\hline $\begin{array}{l}\text { 8. Total EI } \\
\text { Score }\end{array}$ & .21 & .11 & .12 & .25 & $.79^{*}$ & $0.60 *$ & $.44^{*}$ & 1 & & & & & & \\
\hline $\begin{array}{l}\text { 9. Affective } \\
\text { response }\end{array}$ & -.19 & .09 & -.06 & -.12 & .31 & 0.04 & -.11 & .19 & 1 & & & & & \\
\hline $\begin{array}{l}\text { 10. Emotion } \\
\text { regulation }\end{array}$ & .10 & .08 & -.23 & .01 & .25 & 0.07 & .01 & .22 & $.36^{*}$ & 1 & & & & \\
\hline $\begin{array}{l}\text { 11. Perspective } \\
\text { taking }\end{array}$ & .33 & .09 & -.01 & .27 & $.38^{*}$ & 0.19 & -.01 & $.36^{*}$ & .25 & $.54 *$ & 1 & & & \\
\hline $\begin{array}{l}\text { 12. Self-other } \\
\text { awareness }\end{array}$ & .14 & .12 & .04 & .18 & $.49 *$ & 0.15 & -.01 & $.42^{*}$ & $.43^{*}$ & $.37 *$ & $.58^{*}$ & 1 & & \\
\hline $\begin{array}{l}\text { 13. Empathetic } \\
\text { attitudes }\end{array}$ & .12 & .07 & -.03 & .11 & .22 & 0.17 & .13 & .28 & .29 & .31 & $.40 *$ & $.40 *$ & 1 & \\
\hline $\begin{array}{l}\text { 14. Total } \\
\text { Empathy Score }\end{array}$ & .17 & .12 & -.10 & .14 & $.45^{*}$ & 0.17 & .01 & $.40^{*}$ & $.60 *$ & $.76^{*}$ & $.82 *$ & $.75^{*}$ & $.63 *$ & 1 \\
\hline
\end{tabular}

